\title{
Steam reforming of tars at low temperature and elevated pressure for model tar component naphthalene
}

\author{
Michael Speidel, Holger Fischer
}

\begin{abstract}
:
A process of pressurized gasification and power generation in a hybrid system of Solid Oxide Fuel Cell (SOFC) and gas turbine enables an efficient use of biomass. This process requires tar reforming in order to protect the SOFC from plugging. Tars must be converted at 5 bar absolute pressure (bara) while avoiding secondary steam reforming of methane in order to reduce the required heat input for the tar reformer. This can be realized at low reforming temperatures $\left(<700_{-} C\right)$ where methane conversion is reduced due to chemical equilibrium. A laboratory-scale test rig is introduced, which enables an investigation of the steam reforming of the model tar component naphthalene at up to 5 bara. Deactivation of the nickel catalyst caused by coke formation was detected. Despite the reduced amount of free active centers on the catalyst surface, stationary naphthalene conversions are possible at temperatures between $600 \_\mathrm{C}$ and $700 \_\mathrm{C}$. The lower the temperature, the more active centers are covered. For stationary conditions a hyperbolic approach for the reaction rate of steam reforming of naphthalene is developed and parameters for $650 \_\mathrm{C}$ and $700^{\circ} \mathrm{C}$ are determined.
\end{abstract}

